\title{
Match Rates into Family Medicine among Regional Medical Campus Graduates, 2007-2009
}

\author{
Winston Liaw, MD, MPH, Craig Cheifetz, MD, Sarina Luangkhot, Michael Sheridan, ScD, \\ Andrew Bazemore, MD, MPH, and Robert L. Phillips, MD, MSPH
}

Background: Regional medical campuses (RMCs) are geographically separate from parent campuses, have administrative ties to deans' offices, and offer at least 4 third-year clerkships. This study sought to describe the match rates into family medicine for graduates of RMCs and non-RMCs.

Methods: The authors obtained the 2007 to 2009 match lists from schools participating in the Association of American Medical College's Group on Regional Medical Campuses. RMC match numbers for family medicine were subtracted from the total number of family medicine matched US seniors as published by the National Residency Match Program. The outcome of interest was the relative frequencies of RMC and nonRMC graduates matching into family medicine.

Results: Between 2007 and 2009, 261 graduates from 29 RMCs accounted for $8 \%$ of all family medicine matches. During the study period, the match rate into family medicine for RMC graduates was $80 \%$ higher than that of non-RMC graduates (14.2\% vs $7.9 \%$ for all 3 years). In 2009 , only 3 of the RMCs had family medicine match rates lower than that of non-RMCs (7.5\%).

Conclusions: The RMC match rate into family medicine was nearly twice that of non-RMCs. RMCs may play a role in addressing physician workforce imbalances. (J Am Board Fam Med 2012;25:894-907.)

Keywords: Career Choice, Family Medicine, Health Policy, Medical Education

In 2005, after 25 years of relatively stable matriculation into allopathic medical schools, the Council on Graduate Medical Education and the Association of American Medical Colleges (AAMC) called for existing medical school enrollment to increase by $15 \%$ and 30\%, respectively. ${ }^{1,2}$ Medical schools and state legislatures responded to these calls by increasing capacity at existing campuses, building new medical schools, and developing regional medical campuses (RMCs). ${ }^{3}$ Simultaneously, osteopathic school capacity expanded nearly 50\% between 2000 and 2008, whereas offshore training opportunities also increased. $^{4,5}$

This article was externally peer reviewed.

Submitted 14 December 2011; revised 30 May 2012; accepted 31 May 2012.

From Virginia Commonwealth University, Fairfax, VA (WL, CC, SL, MS); and the Robert Graham Center, Washington, $\mathrm{DC}$ ( $\mathrm{AB}, \mathrm{RLP})$.

Funding: none.

Conflict of interest: none declared.

Corresponding author: Winston Liaw, MD, MPH, Virginia Commonwealth University, 3650 Joseph Siewick Drive, \#400, Fairfax, VA 22033 (E-mail: winstonrliaw@gmail.com).
There has long been debate about the adequacy of our medical workforce. Recent commentary has focused on purported shortages in the physician workforce, whereas others contend that the real issue is inadequate distribution into specialties and geographies where need is greatest and a composition unrepresentative of the US population. ${ }^{6-8}$ The future primary care workforce is an area of particular concern with Colwill $^{9}$ projecting that an increased primary care workload, due to population growth and aging, and shrinking pipeline will lead to a shortage of 44,000 generalists by 2025 . Massachusetts' experience with longer wait times for the publicly insured seeking primary care after insurance expansion has many worried about the impact of not having appropriate access. ${ }^{10}$ Insurance expansion for 34 million additional Americans after passage of the Patient Protection and Affordable Care Act provides another incentive for medical education to respond to community workforce needs so that access does not suffer. ${ }^{11-13}$ Numerous factors influence specialty composition and distribution. The absence of coordinated planning and targeted policies has contributed to our current 
state of physician maldistribution and increasing specialization. ${ }^{14,15}$ Policymakers now have an opportunity to collaborate with educators to ensure that the medical workforce can appropriately respond to the anticipated surge in demand.

RMCs have been promoted as a cost-effective way to increase enrollment. By using existing infrastructure and faculty, RMCs benefit from lower startup costs compared with the construction of new medical schools although the data regarding their cost-effectiveness are anecdotal. ${ }^{16}$ According to an AAMC report on RMCs, the 1970 Carnegie Commission on Higher Education called for an increase in medical school enrollment and identified 9 cities that would benefit from new medical schools. ${ }^{17}$ Six of the 9 cities decided to develop RMCs affiliated with existing schools rather than build new schools. In Florida, state officials weighed various options regarding medical education expansion such as building a new medical school or developing an RMC. They ultimately chose to create an RMC because it proved to be the more cost-effective option. ${ }^{18}$

Many RMCs were created after policymakers recognized the potential of these campuses to improve the health of surrounding communities, but data are lacking regarding their impact on medical student career choice. Two examples of RMCs designed to address the needs of rural communities suffering from a shortage of physicians are the WWAMI program (Washington, Wyoming, Alaska, Montana, and Idaho) and the University of Alabama Huntsville Campus. The WWAMI program through the University of Washington, School of Medicine was created to address the needs of adjacent states. Because these states are mostly rural, they contain significant underserved regions but lack the funds to build their own instate medical schools. ${ }^{19}$ The University of Alabama School of Medicine developed the Huntsville Campus with the belief that community-based branch campuses would produce more primary care physicians for the region. ${ }^{17}$ Assessments of RMCs, thus far, have focused on campuses affiliated with a single parent institution, and few that we know of have assessed their impact on career paths. A study of students at a medical school in Kentucky with an RMC reported that $33 \%$ of the RMC graduates went into family medicine compared with $13 \%$ from the non-RMC campus. ${ }^{20}$

Over the past 15 years, primary care production has dropped to $<25 \%$ of all residency training and primary care residency fill rates by US graduates is near a nadir-only $42.4 \%$ of family medicine residency positions filled in the annual match with US medical graduates in 2009 (compared with $72.6 \%$ in 1996). ${ }^{21,22}$ This decline in interest in family medicine and primary care has dire consequences as studies have found that lower primary care physicianto-population ratios are associated with higher per beneficiary Medicare expenditures and lower quality. ${ }^{23}$ In response to this precipitous decline, educators and policymakers have sought to identify the curricular, institutional, and student factors that will bolster the primary care workforce. ${ }^{24}$ To our knowledge, this is the first analysis of RMCs on an aggregate level to examine whether exposure to RMCs is associated with differences in specialty selection. Our objective was to determine whether students graduating from RMCs in 2007 to 2009 were more likely than those graduating from non-RMCs to enter family medicine residencies.

\section{Methods}

The study design was a retrospective cohort analysis. We included US medical school graduates from 2007 to 2009 who successfully matched in the National Residency Matching Program match. The RMC cohort consisted of graduates from 2007 to 2009 who successfully matched and attended an RMC. We obtained the residency match lists from RMCs participating in the AAMC's Group on Regional Medical Campuses (GRMC). We focused on match information because it is more reflective of student choice than postscramble residency fill rates (ie, students who do not match and the residencies in which they ultimately enter). At the time of the study, there were 42 individual RMCs in the GRMC. Members of the GRMC are self-identified as RMCs. Some parent schools have multiple regional campuses, whereas several schools have not yet produced graduates. This analysis was part of a larger GRMC initiative to determine whether graduates of RMCs were more or less likely than graduates of non-RMCs to match into any particular specialties.

The AAMC now recognizes a variety of RMC models, depending on the amount of time spent at the RMC. These categories are currently being refined and are not yet publicly available. Generally, RMCs can be grouped into 3 categories: (1) basic science RMCs (where students spend their 
first and second years at the RMCs); (2) clinical RMCs (where students spend their third and fourth years at the RMCs); and (3) combined RMCs (where students spend a portion of basic science and clinical years at the RMCs). Our sample consisted of RMCs that satisfied the criteria published by the AAMC in 2003, defining RMCs as entities that are geographically separate from the parent campus, have an administrative tie to the office of the dean (not just departmental ties), and offer at least 4 of the required third-year clerkships.

We excluded (1) graduates who matched in specialties that do not participate in the National Residency Matching Program such as ophthalmology and urology; (2) those who did not match (including those graduates who ultimately scrambled for residency positions after the match); and (3) transitional and preliminary program matches. For graduates matching into transitional and preliminary programs, we assessed their specialty after intern year to avoid counting them twice. We subtracted RMC match numbers for each specialty from the total number of matched US seniors per specialty as published by the National Residency Matching Program. ${ }^{25}$ The outcome of interest was the percentage of matched graduates matching in family medicine residencies for RMC and nonRMC US seniors. This was calculated by dividing the number of graduates matched into family medicine by the total number of matched graduates for RMCs and non-RMCs.

The null hypothesis was that there was no difference in the frequency of matches into family medicine residencies by RMC and non-RMC graduates. A Pearson $\chi^{2}$ test was used to refute the null hypothesis with a threshold of $P<.05$ for statistical significance. All analyses were conducted using SAS software (Version 9.2; SAS Institute, Cary, NC).

The Institutional Review Board of Inova Health System issued a Certificate of Exemption for this study under DHHS 45-CFR-46-101.b.

\section{Results}

Twenty-nine RMCs participated in this analysis (Table 1), whereas 4 RMCs were excluded because they had not yet participated in the match. ${ }^{26}$ Our sample consisted of the 1832 graduates from RMCs and the 38,955 graduates from non-RMCs who successfully matched (Table 2). On average, 5.8 third and 1.9 fourth-year (or 7.7 third- and fourth- year courses) courses are required to be taken at each of the RMCs (Table 3).

Between 2007 to 2009, the match rate into family medicine for RMC graduates was $80 \%$ higher than that of non-RMC graduates $(14.2 \%$ vs $7.9 \%$ for all 3 years; Figure 1). Therefore, compared with non-RMCs, for every 16 medical students trained in RMCs, 1 additional student will match in a family medicine residency. Despite this difference, RMC graduates represent a small percentage of the total medical student population, making up $8 \%$ of all the family medicine matches. For individual years, the match rate into family medicine for RMCs was nearly twice that of non-RMCs. The differences within each year were statistically significant $(P<.0001)$. The majority of RMCs in our sample demonstrated a high percentage of RMC graduates going into family medicine. In 2009, only 3 of the RMCs had a family medicine match rate lower than the non-RMC rate (Figure 2).

\section{Discussion}

From 2007 to 2009, graduates from RMCs were nearly twice as likely as those graduating from nonRMCs to match in family medicine. Primary care is struggling to attract students, and this association has important implications regarding how medical school expansion can address physician workforce composition deficiencies. It can also impact the distribution of the workforce because family physicians are more likely to practice in rural and underserved areas than most other specialties with approximately $20 \%$ of family physicians practicing in rural geographies. ${ }^{27,28}$ This latter outcome was not measured directly but will be important to monitor as these graduates complete their residencies and move into direct patient care.

Little is known about RMCs on an aggregate level. Most of the existing data is based on individual schools, although medical student evaluations of these entities have generally been positive. ${ }^{17}$ With fewer residents and fellows at these campuses, medical students often benefit from more direct and prolonged interaction with attendings, more intense involvement with patient care, and support from an infrastructure whose primary focus is typically on medical student education. Furthermore, educators at RMCs are often less burdened by administrative layers, allowing for the development of innovative, responsive curricula. ${ }^{17}$ Historically, 
Table 1. Graduates Matching into Family Medicine per Year per Regional Medical Campus

\begin{tabular}{|c|c|c|c|}
\hline \multirow[b]{2}{*}{ Parent University/Regional Campus Location(s) } & \multicolumn{3}{|c|}{ Number of Matched Graduates } \\
\hline & 2007 & 2008 & 2009 \\
\hline \multicolumn{4}{|l|}{ Florida State University College of Medicine: } \\
\hline Daytona Beach, Orlando, Sarasota, Fort & 46 & 47 & 62 \\
\hline \multicolumn{4}{|l|}{ Pierce, Pensacola, Tallahassee } \\
\hline \multicolumn{4}{|l|}{ Michigan State University College of Medicine: } \\
\hline Flint, Grand Rapids, Kalamazoo, Lansing, Saginaw, Upper Peninsula & 110 & 92 & 79 \\
\hline Robert Wood Johnson Medical School: & 53 & 47 & 41 \\
\hline Camden & & & \\
\hline \multicolumn{4}{|l|}{ University of Alabama School of Medicine: } \\
\hline Huntsville & 23 & 26 & 25 \\
\hline Tuscaloosa & 21 & 25 & 22 \\
\hline \multicolumn{4}{|l|}{ University of California, Los Angeles: } \\
\hline Charles Drew & 19 & 19 & 26 \\
\hline \multicolumn{4}{|l|}{ University of Illinois College of Medicine: } \\
\hline Rockford & 42 & 42 & 41 \\
\hline Urbana & 20 & 28 & 15 \\
\hline \multicolumn{4}{|l|}{ University of Kansas School of Medicine Wichita: } \\
\hline Wichita & 49 & 47 & 59 \\
\hline \multicolumn{4}{|l|}{ University of Oklahoma College of Medicine: } \\
\hline Tulsa & 22 & 24 & 33 \\
\hline \multicolumn{4}{|l|}{ University of Texas Medical Branch: } \\
\hline Austin & 15 & 15 & 29 \\
\hline \multicolumn{4}{|l|}{ University of Washington-WWAMI: } \\
\hline Washington, Wyoming, Alaska, Montana, Idaho & 127 & 115 & 148 \\
\hline \multicolumn{4}{|l|}{ Virginia Commonwealth University School of Medicine: } \\
\hline Fairfax & 24 & 24 & 20 \\
\hline \multicolumn{4}{|l|}{ West Virginia University School of Medicine: } \\
\hline Charleston & 29 & 24 & 33 \\
\hline Eastern & 7 & 8 & 9 \\
\hline Total & 607 & 583 & 642 \\
\hline
\end{tabular}

RMCs have been geographically characterized by their distance from urban academic health centers and typically situated in suburban and rural communities. The exposure to rural and communitybased practices may be more nurturing to medical students interested in primary care. However, more research is needed to explain the mechanisms be- hind this relationship and to confirm that this relationship holds when controlling for the numerous confounders that influence specialty choice.

\section{Limitations}

Interpretation of these results requires caution, and numerous limitations should be taken into account.

Table 2. Graduates Matching into Family Medicine by Regional Medical Campus

\begin{tabular}{lccccc}
\hline & \multicolumn{2}{c}{ Regional Medical Campuses } & & \multicolumn{2}{c}{ Nonregional Medical Campuses } \\
\cline { 2 - 3 } Year & Matched in Family Medicine & Total Matched & & Matched in Family Medicine & Total Matched \\
\hline 2007 & 87 & 607 & 1009 & 12,788 \\
2008 & 88 & 583 & 1068 & 12,950 \\
2009 & 86 & 642 & 985 & 13,217 \\
Total & 261 & 1832 & 3062 & 38,955 \\
\hline
\end{tabular}




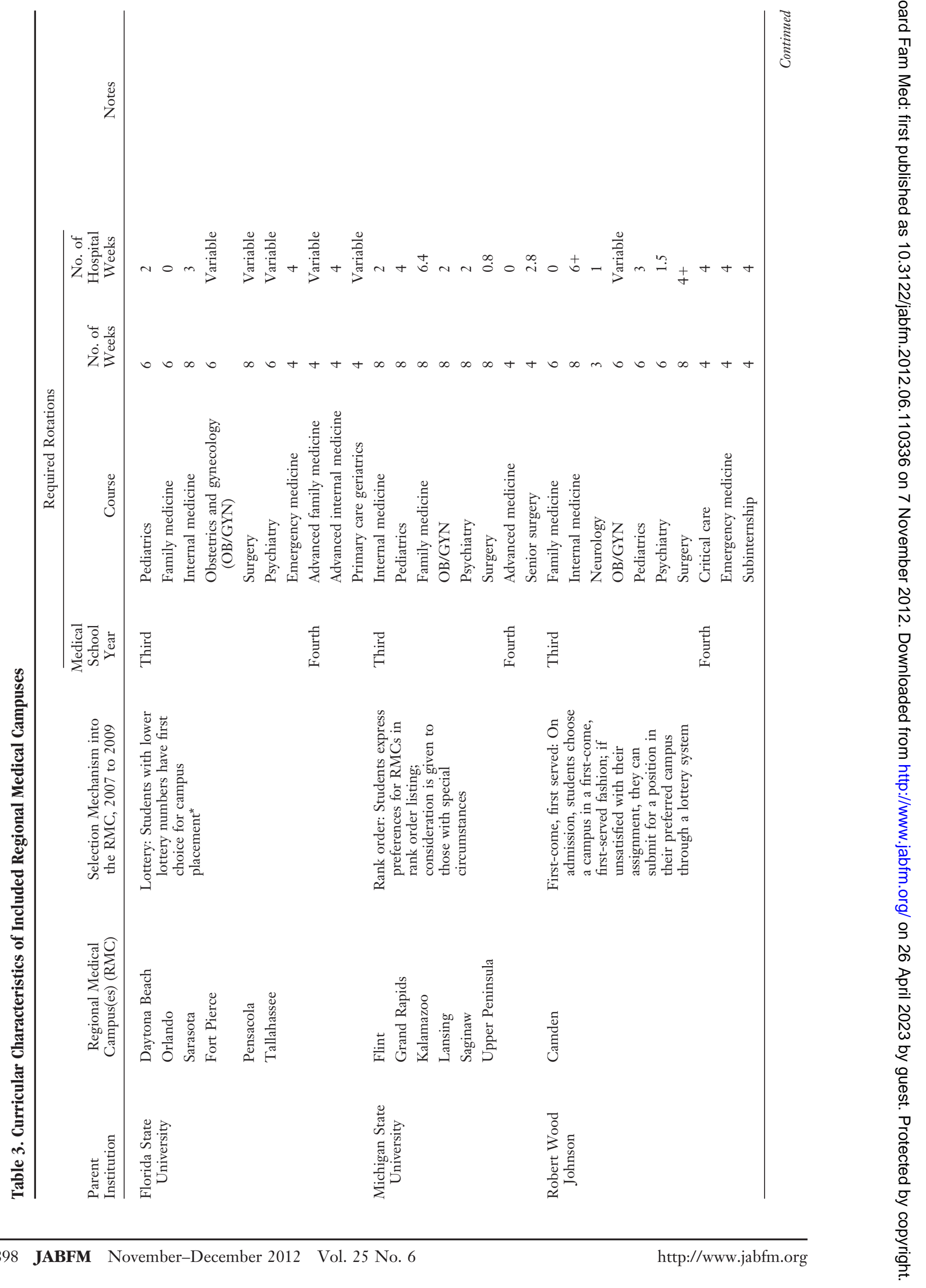




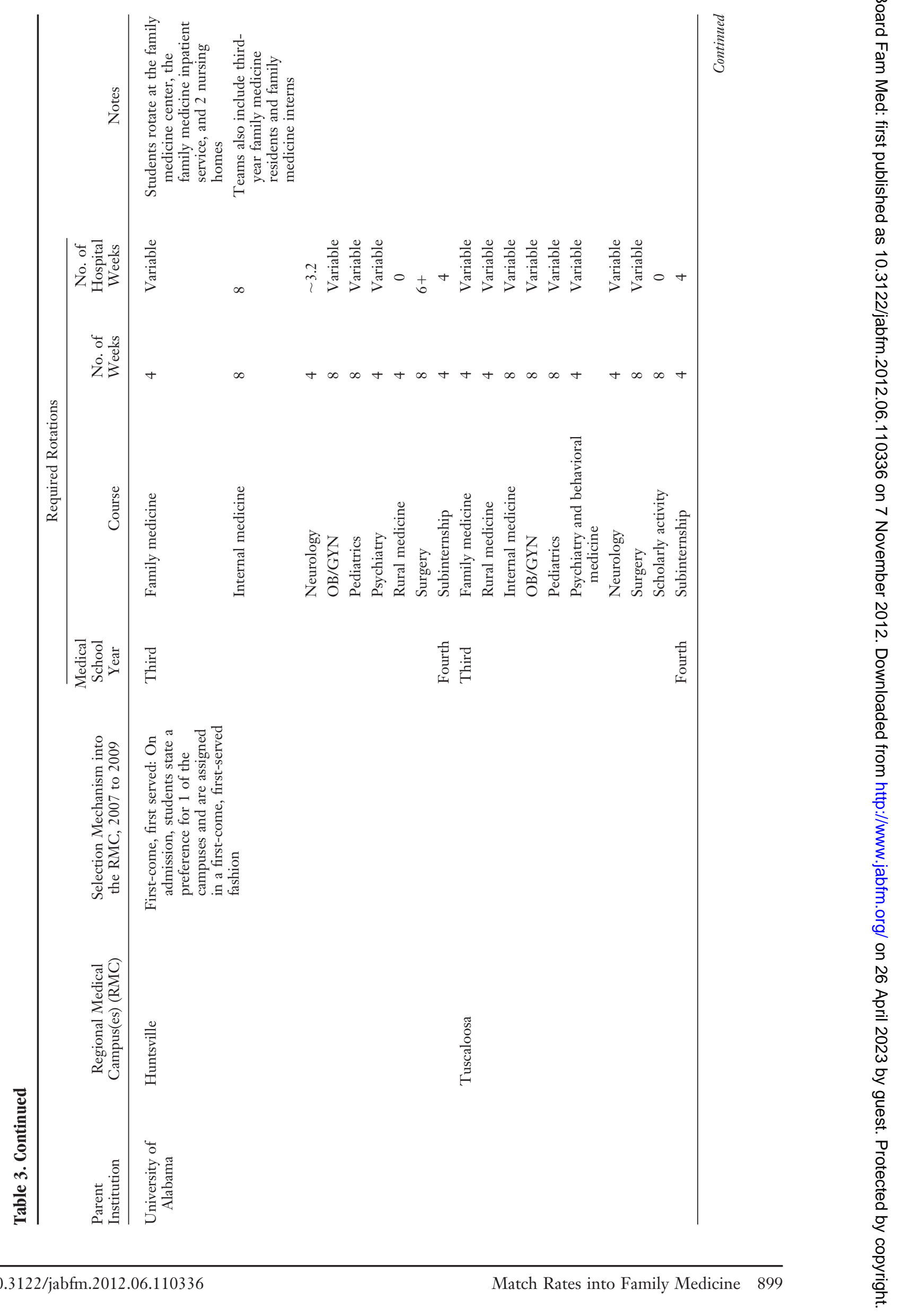




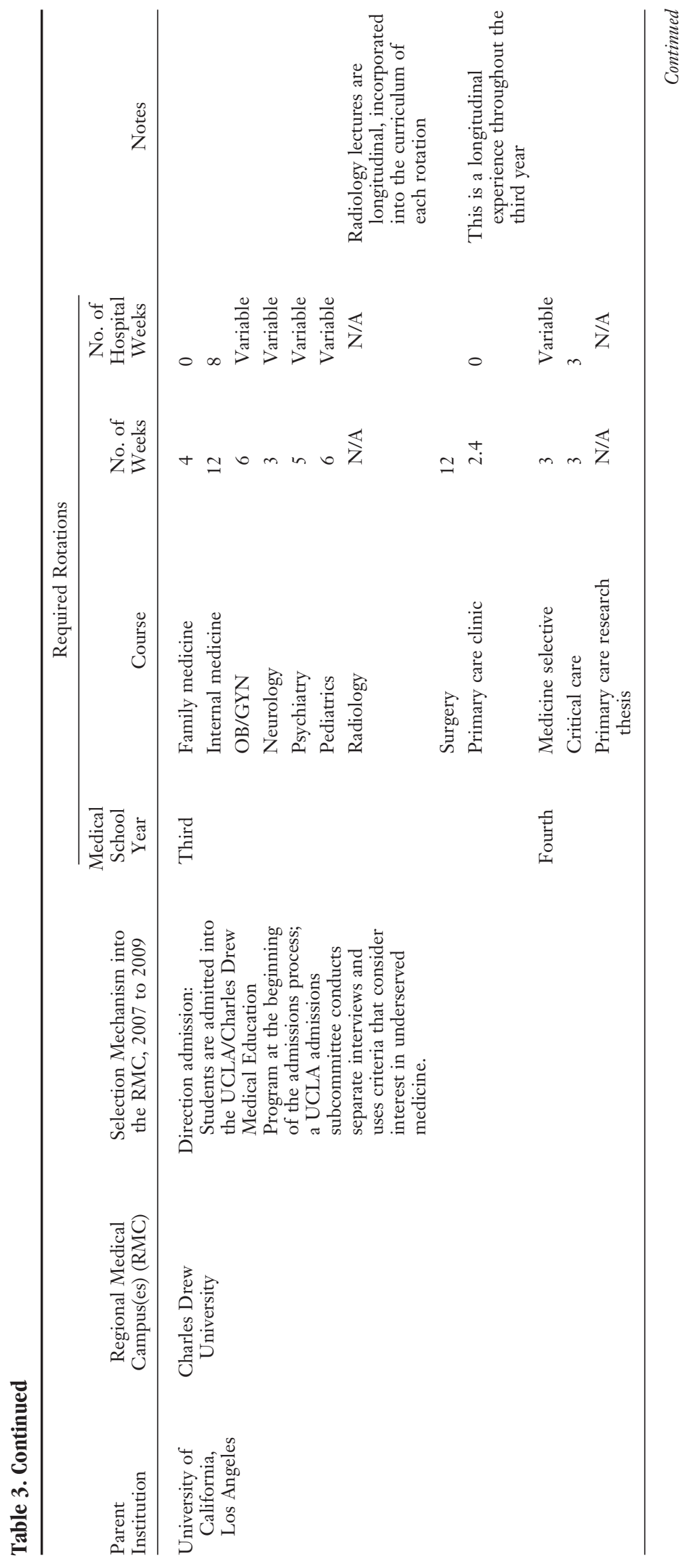




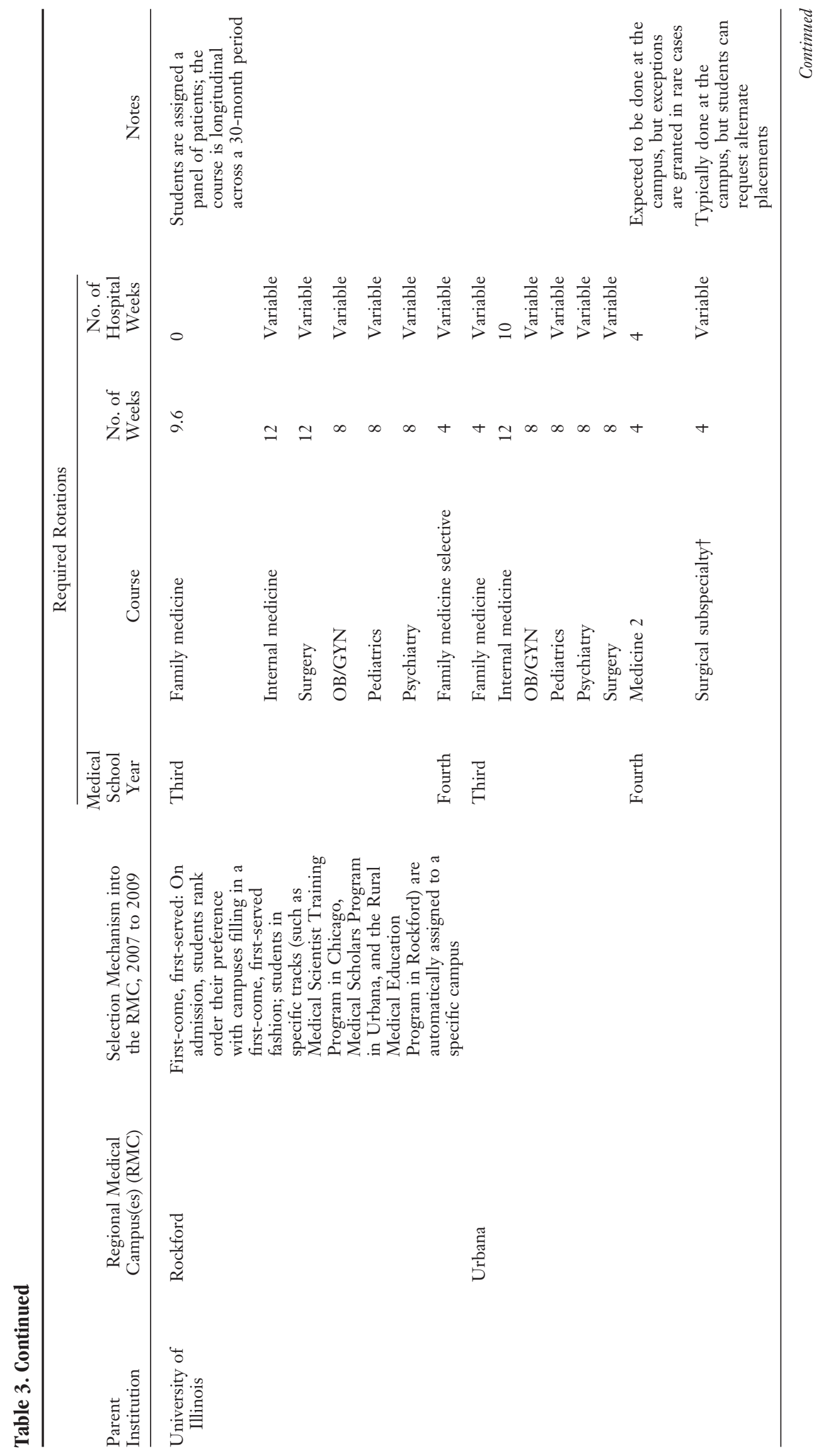




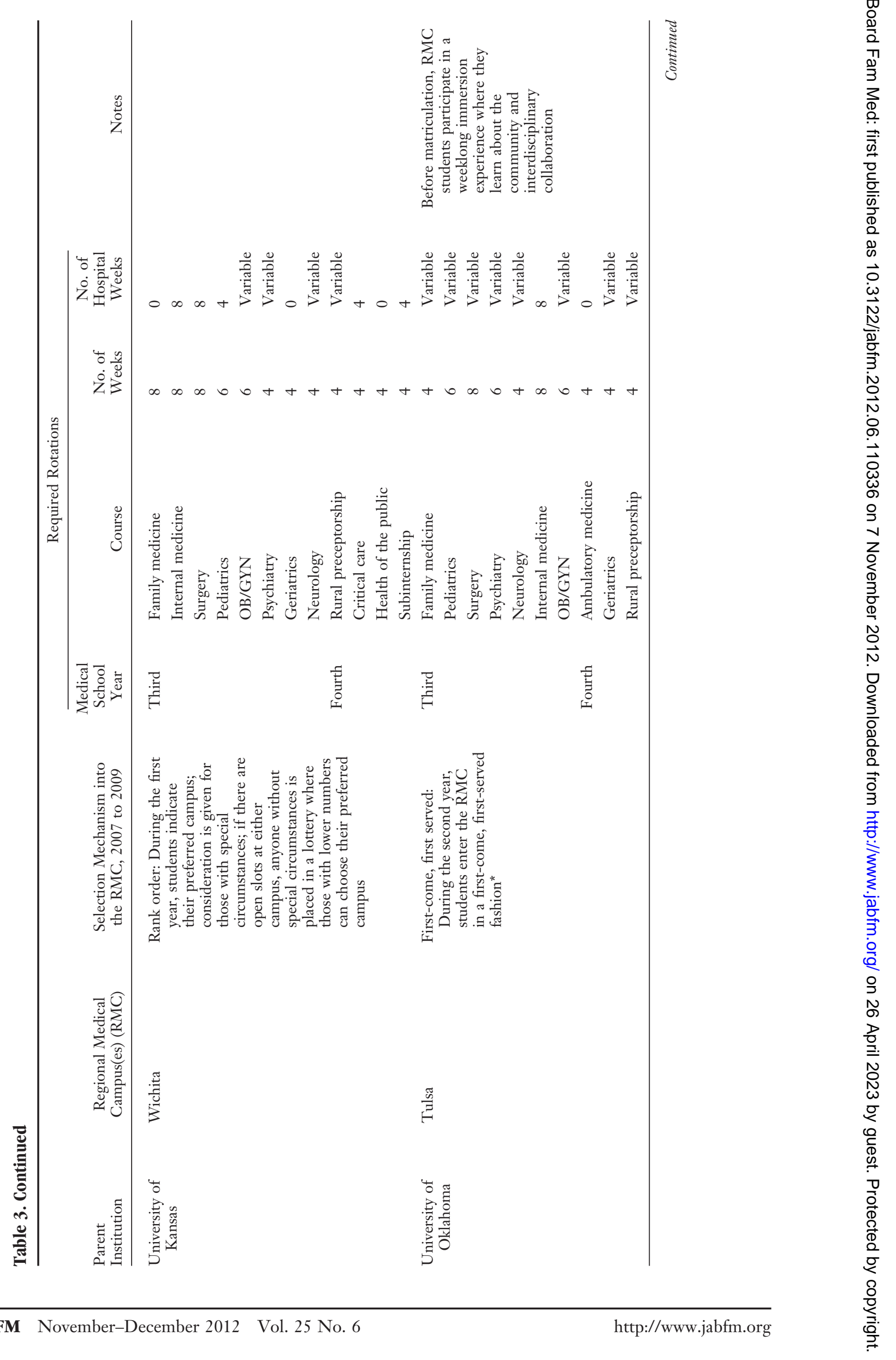




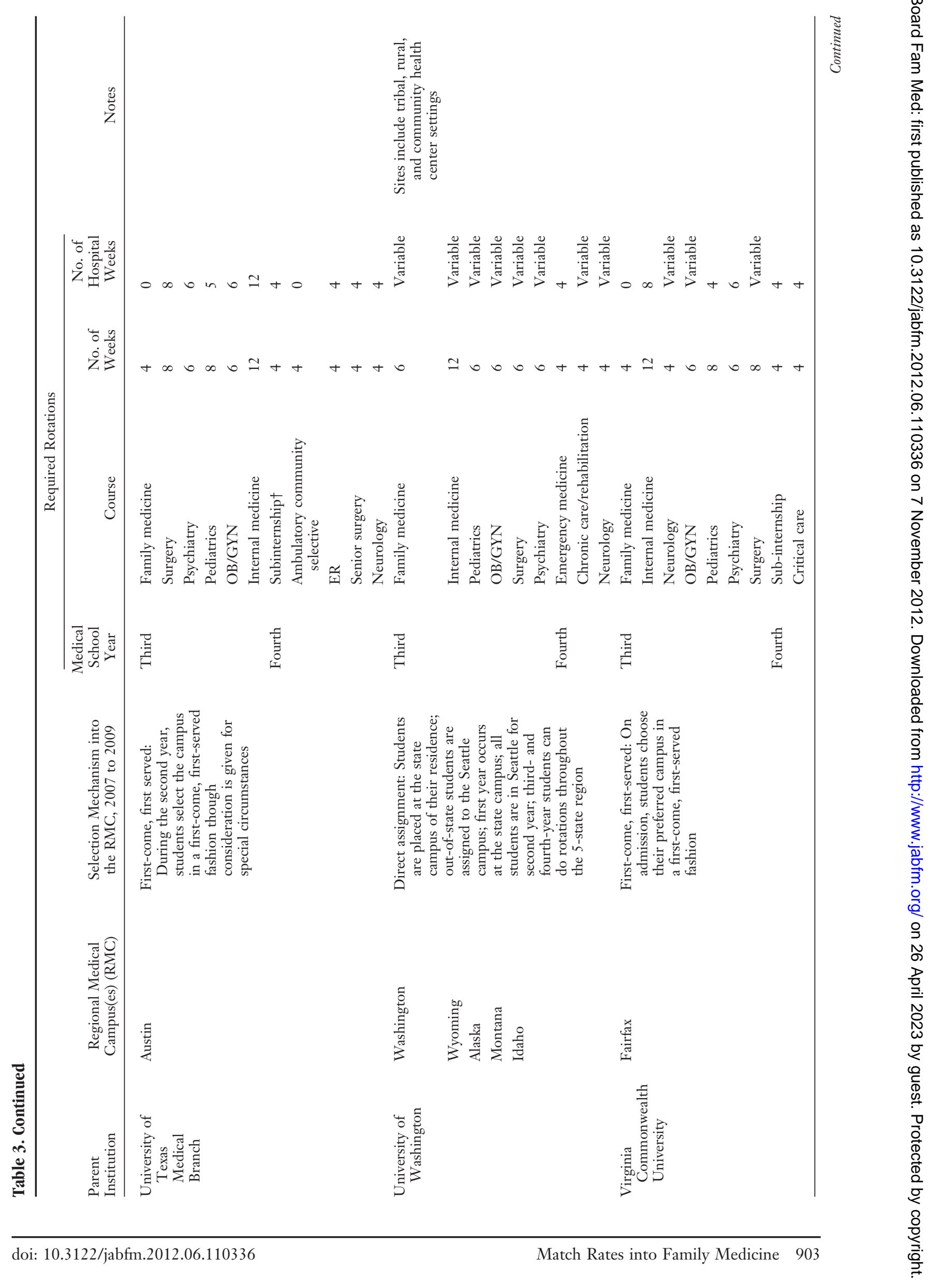




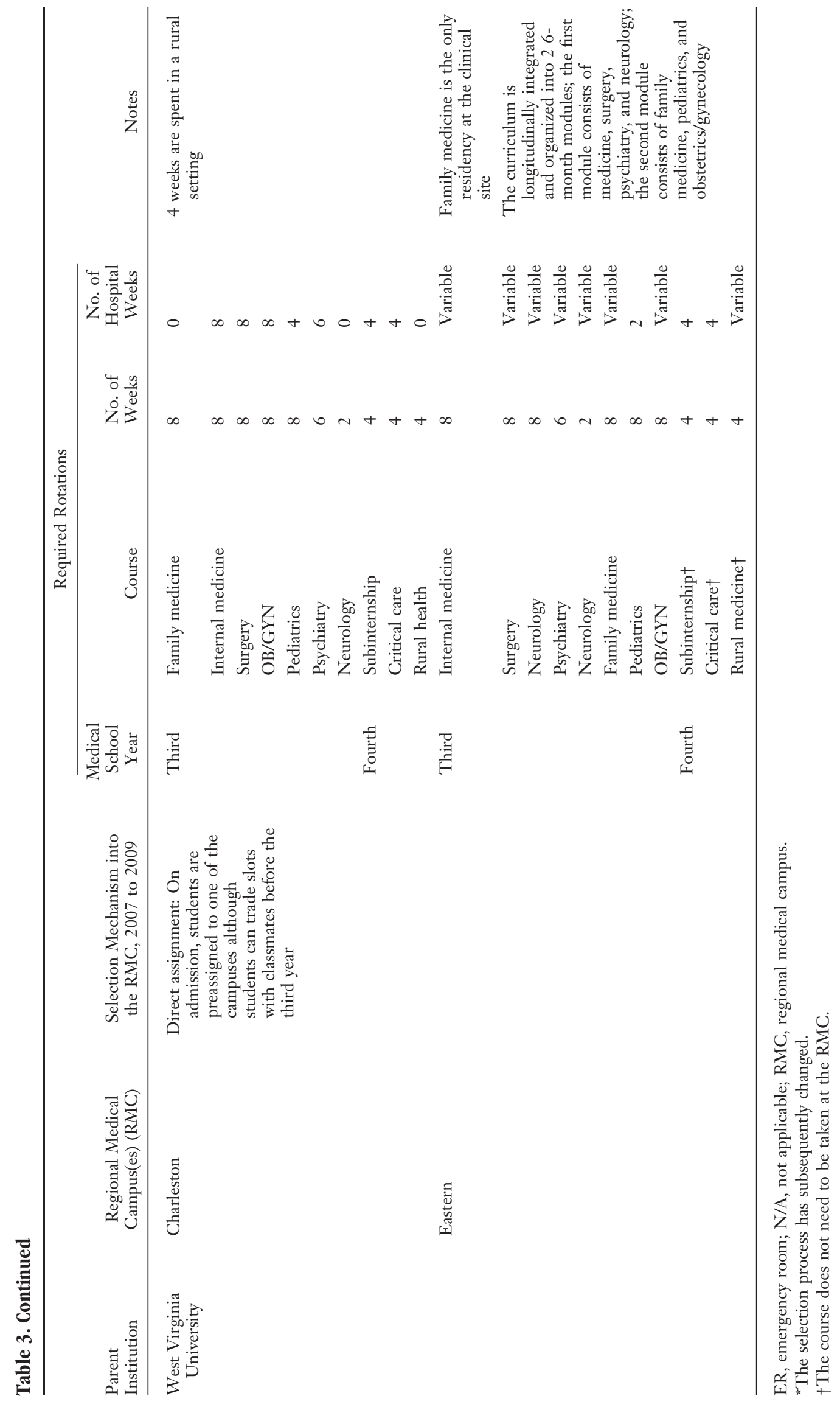


Figure 1. Percentage of graduates matching in family medicine, by regional medical campus.

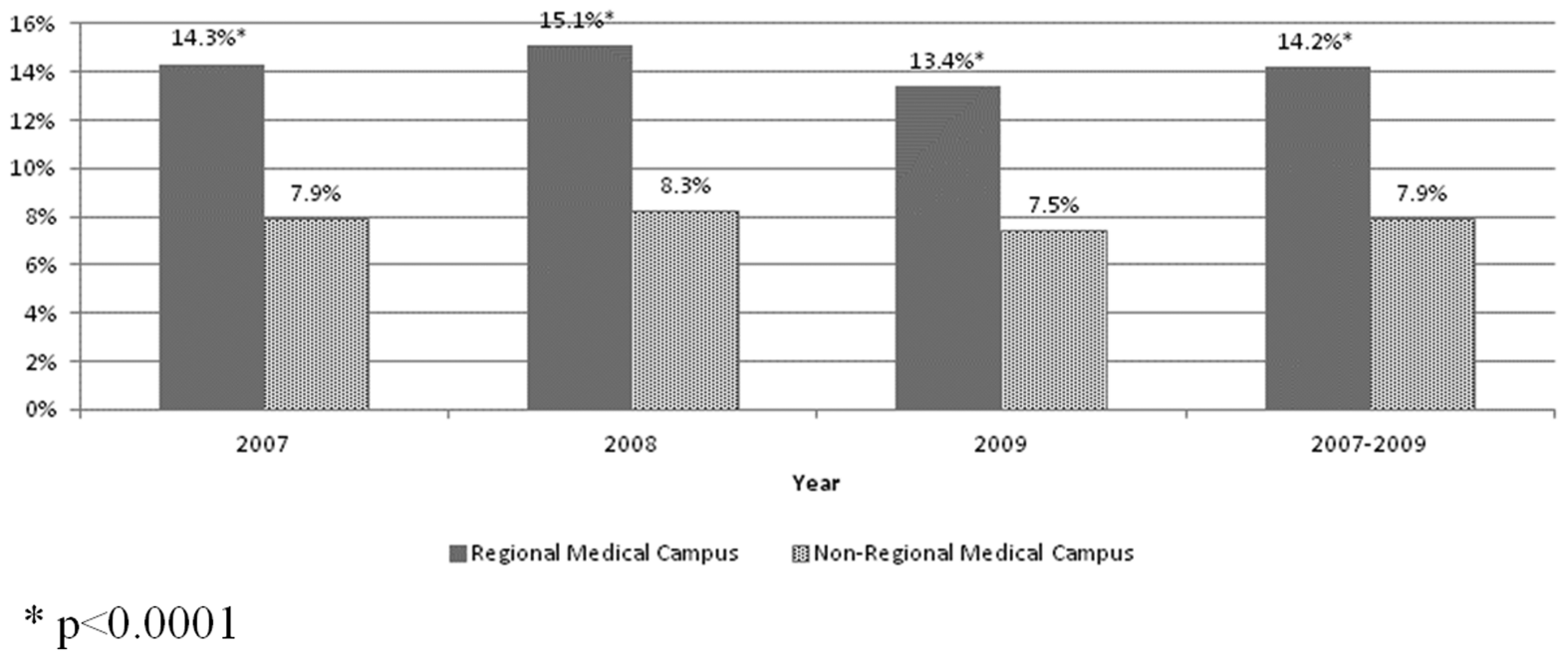

Lacking a consensus definition for RMCs, we studied the cohort of RMCs who were self-identified members of a national RMC coalition (GRMC) who also satisfied a definition of RMC published by the AAMC in $2003 .{ }^{17}$ It is possible that this selection process excluded RMCs who were not GRMC members. Currently, the GRMC is working to standardize RMC definitions. Second, the amount of time spent away from the parent campus and type of training exposure may vary across RMCs. For example, students participating in WWAMI typically spend the first year at their assigned state campus. All students are in Seattle for the second year, whereas the third and fourth years can be spent doing rotations throughout the 5-state region. Pure RMC and non-RMC cohorts do not exist in this model. We included the WWAMI program because it fulfilled our inclusion criteria and contend that its inclusion does not skew our results appreciably. Removing the WWAMI students from the 2009 RMC cohort decreases the percentage matching into family medicine by only $0.2 \%$. Lack of more definitive information limits our ability to extrapolate our findings to the pro-

Figure 2. Percent matched in family medicine, by regional medical campus, 2009.

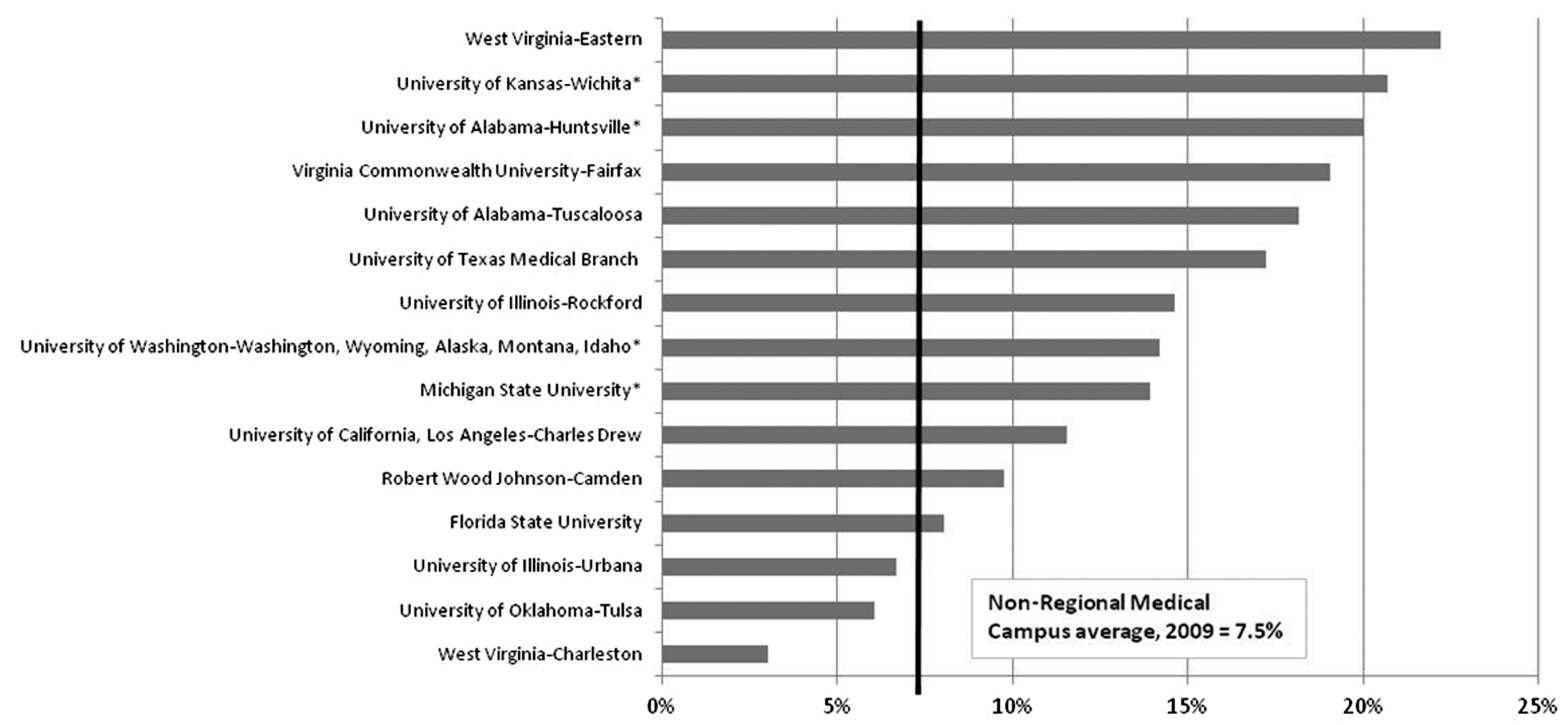

* $\mathrm{p}<0.05$, compared to the percentage of non-regional medical campus graduates matching into family medicine, 2009 
jected impact of RMCs on the primary care workforce.

Furthermore, we included only graduates who matched through the National Residency Matching Program, so our data may be inaccurate if RMC and parent institution nonmatch rates are different. Graduates may have also ranked residencies in other specialties ahead of family medicine; therefore, match rates may not perfectly align with graduate preferences. Another limitation is that our outcome measure captures RMC graduates as they enter family medicine residency and does not provide a measure of the number of graduates ultimately practicing primary care. Based on our analyses of other specialties, the percentage of RMC graduates matching into internal medicine in 2009 was $14.8 \%$ compared with $19.2 \%$ of non-RMC graduates $(P=.006)$, suggesting that there may not be an overall increase in the number of medical students going in to primary care specialties but rather a shift from internal medicine to family medicine (the differences between the percentages of graduates for RMCs and non-RMCs going into medicine/pediatrics and pediatrics were not statistically different). Nevertheless, given reports indicating a decreasing percentage of internal medicine residents choosing careers in primary care, a shift in residents to family medicine may ultimately lead to an increased production of primary care physicians. $^{29}$

Finally, due to limitations with our data source, we were unable to control for variables that also influence specialty choice such as rural birth, interest in primary care before matriculation, and exposure to Title VII funding. Admission protocols into RMCs from the parent institution vary widely, ranging from lottery systems to "first-come firstserved," although the selection mechanisms of the RMCs generally allow students to choose the RMC. Even the university that directly assigns students to a campus provides opportunities for them to subsequently trade slots. Thus, selection bias could also affect our findings if RMC cohorts consist of students already more likely to pursue primary care. This study was envisioned as an important first step in the assessment of RMC impact and one that begs for further understanding of variable factors across RMCs and their impact on social accountability outcomes.

The effects of the significant resources currently invested in RMC expansion require more detailed analyses so that policymakers, planners, taxpayers, and deans can make informed decisions about allocating scarce resources to medical education and workforce growth. There is increasing capacity and interest in using "footprinting" techniques, and tools such as the Med School Mapper (www.medschool mapper.org), to evaluate the impact of medical schools on their communities, states, and regions. The ability to differentiate the impact of RMCs from parent campuses should be improved to continue monitoring their effect. A better understanding and greater consensus among US medical educators as to appropriate measures of social accountability of medical schools are also needed. ${ }^{30}$ Specific to the findings of our analysis, it will be important to analyze whether the percentage of graduates matching in family medicine differs across the RMCs and remains to be seen whether the RMCs that have recently developed in response to calls for expansion behave similarly to RMCs built in the 1970s. This would help to clarify the specific RMC characteristics that are particularly salient to primary care production and provide guidance for future RMCs. Finally, additional research is needed to determine whether graduates of these institutions are more likely to practice in shortage areas, rural areas, and community health centers.

\section{References}

1. Council on Graduate Medical Education. Sixteenth report: physician workforce policy guidelines for the United States, 2000-2020. Rockville (MD): Health Resources and Services Administration; 2005.

2. Association of American Medical Colleges. Statement on the physician workforce. Available at www.aamc.org/download/55458/data/workforceposition. pdf. Accessed March 23, 2012.

3. Association of American Medical Colleges. Medical school expansion plans: results of the 2006 AAMC survey. Available at: www.aamc.org/download/55444/data/ 2006medschoolexpansion.pdf. Accessed March 23, 2012.

4. American Association of Colleges of Osteopathic Medicine. Total enrollment in U.S. osteopathic medical schools (summary). Available at: www. aacom.org/about/fastfacts/Documents/Summaries/ FF-Total-enrollment-summary.pdf. Accessed March 23, 2012.

5. Eckhert NL. Perspective: private schools of the Caribbean: outsourcing medical education. Acad Med 2010;85:622-30.

6. Lindsay D, Bazemore AW, Bowman R, Petterson S, Green LA, Phillips RL. Will medical school expansion help to diversify the physician workforce? Am Fam Physician 2007;76:38. 
7. Green LA, Dodoo MS, Ruddy G, Fryer GE, Phillips RL, McCann JL, et al. The physician workforce of the United States: a family medicine perspective. Washington (DC): The Robert Graham Center; 2004.

8. Turner EF, Bazemore AW, Phillips RL, Green LA. Will patients find diversity in the medical home? Am Fam Physician 2008;78:183.

9. Colwill JM, Cultice JM, Kruse RL. Will generalist physician supply meet demands of an increasing and aging population? Health Aff (Millwood) 2008;27: w232-41.

10. Long SK, Stockley K. Emergency department visits in Massachusetts: Who uses emergency care and why? Available at: www.rwjf.org/files/research/48929.pdf. Accessed March 23, 2012.

11. National Governors Association. National Association of State Budget Officers. The Fiscal Survey of States. Available at: www.nasbo.org/sites/default/ files/fsspring2009.pdf. Accessed March 23, 2012.

12. Centers for Medicare and Medicaid Services. Estimated financial effects of the 'Patient Protection and Affordable Care Act,' as amended. Available at: www. cms.gov/ActuarialStudies/Downloads/PPACA_ 2010-04-22.pdf. Accessed March 23, 2012.

13. Mullan F, Chen C, Petterson S, Kolsky G, Spagnola $M$. The social mission of medical education: ranking the schools. Ann Intern Med 2010;152:804-11.

14. Council on Graduate Medical Education. Tenth report: physician distribution and health care challenges in rural and inner-city areas. Rockville (MD): Health Resources and Services Administration; 1998.

15. Council on Graduate Medical Education. Twentieth report: advancing primary care. Rockville (MD): Health Resources and Services Administration; 2010.

16. Report of the Council on Medication Education. US medical school expansion. CME Report 16-A10. Chicago: American Medical Association, 2010. Available at: www.ama-assn.org/ama1/pub/upload/ mm/377/cme-rep16-a10.pdf. Accessed March 23, 2012.

17. Association of American Medical Colleges. MiniMed: the role of regional medical campuses in US medical education. Washington (DC): Association of American Medical Colleges; 2003.

18. Rackleff LZ, O'Connell MT, Warren DW, Friedland ML. Establishing a regional medical campus in southeast Florida: successes and challenges. Acad Med 2007;82:383-9.

19. Norris TE, Coombs JB, House P, Moore S, Wenrich MD, Ramsey PG. Regional solutions to the physician workforce shortage: the WWAMI experience. Acad Med 2006;81:857-62.

20. Crump WJ, Barnett D, Fricker S. A sense of place: rural training at a regional medical school campus. J Rural Health 2004;20:80-4.

21. Pugno PA, McGaha AL, Schmittling GT, DeVilbiss AD, Ostergaard DJ. Results of the 2009 National Resident Matching Program: family medicine. Fam Med 2009;41:567-77.

22. Salsberg E, Rockey PH, Rivers KL, Brotherton SE, Jackson GR. US residency training before and after the 1997 Balanced Budget Act. JAMA 2008;300: 1174-80.

23. Baicker K, Chandra A. Medicare spending, the physician workforce, and beneficiaries' quality of care. Health Aff (Millwood) 2004;W4:184-97.

24. Phillips RL, Dodoo MS, Petterson S, Xierali I, Bazemore A, Teevan B, et al. Specialty and geographic distribution of the physician workforce: what influences medical student and resident choices? Washington (DC): The Robert Graham Center; 2009.

25. Results and data: 2010 main residency match. Washington (DC): National Residency Match Program; 2010.

26. The excluded campuses included Bassett Healthcare, Medical College of Georgia Athens, Texas Tech University School of Medicine Permian Basin, and University of North Carolina School of Medicine Asheville.

27. Grumbach K, Hart LG, Mertz E, Coffman J, Palazzo L. Who is caring for the underserved? A comparison of primary care physicians and nonphysician clinicians in California and Washington. Ann Fam Med 2003;1:97-104.

28. Ruddy GR, Fryer GE, Phillips RL, Green LA, Dodoo MS, McCann JL. The family physician workforce: the special case of rural populations. Am Fam Physician 2005;72:147.

29. Bodenheimer T. Primary care-will it survive? N Engl J Med 2006;355:861-4.

30. Wartman SA. Commentary: academic health centers: the compelling need for recalibration. Acad Med 2010;85:1821-22. 